\title{
$\triangle$-Convergence analysis of improved Kuhfittig iterative for asymptotically nonexpansive nonself-mappings in $W$-hyperbolic spaces
}

\section{Li Yi* and Liu Hong Bo}

"Correspondence: liyi@swust.edu.cn School of Science, Southwest University of Science and Technology, Mianyang, 621010, P.R. China

\section{Springer}

\begin{abstract}
Throughout this paper, we introduce a class of asymptotically nonexpansive nonself-mapping and modify the classical Kuhfittig iteration algorithm in the general setup of hyperbolic space. Also, $\triangle$-convergence results are obtained under a limit condition. The results presented in the paper extend various results in the existing literature.
\end{abstract}

Keywords: asymptotically nonexpansive nonself-mapping; improved Kuhfittig iterative; hyperbolic space; nonexpansive retraction

\section{Introduction}

As we know, fixed point theory proposed in the setting of normed linear spaces or Banach spaces mainly depends on the linear structure of the underlying space. However, a nonlinear framework for fixed point theory is a metric space embedded with a 'convex structure'. The class of hyperbolic spaces, nonlinear in nature, is a general abstract theoretic setting with rich geometrical structures for metric fixed point theory.

In fact, a few important results of the problems in various disciplines of science being nonlinear in nature were studied only in CAT(0) space. In 1976, the concept of $\triangle$-convergence in general metric spaces was coined by Lim [1]. Since then, Kirk and Panyanak [2] specialized this concept to $\mathrm{CAT}(0)$ spaces and proved that it is very similar to the weak convergence in the Banach space setting. Dhompongsa and Panyanak [3] and Abbas et al. [4] obtained $\triangle$-convergence theorems for the Mann and Ishikawa iterations in the CAT(0) space setting. Moreover, Yang and Zhao [5] studied the strong and $\Delta$ convergence theorems for total asymptotically nonexpansive nonself-mappings in CAT(0) spaces. As for more details of this work, one can refer to the aforementioned papers and references therein.

In recent years, hyperbolic space has attracted much attention of many authors. The study of hyperbolic spaces has been largely motivated and dominated by questions about hyperbolic groups. It should be noted that one of the main object of study is in geometric group theory. For example, Wan [6] proved some $\Delta$-convergence theorems in a hyperbolic

O2014 Yi and Bo; licensee Springer. This is an Open Access article distributed under the terms of the Creative Commons Attribution License (http://creativecommons.org/licenses/by/2.0), which permits unrestricted use, distribution, and reproduction in any medium, provided the original work is properly cited. 
space, in which a mixed Agarwal-O'Regan-Sahu type iterative scheme for approximating a common fixed point of totally asymptotically nonexpansive mappings was constructed. In this paper, following the work of Yang and Wan, by introducing a class of asymptotically nonexpansive nonself-mapping, we modify a classical Kuhfittig iteration algorithm in the general setup of hyperbolic space. Under a limit condition, we also establish some $\triangle$-convergence results, which extend various results in the existing literature.

\section{Preliminaries}

In this paper, we work in the setting of hyperbolic spaces introduced by Kohlenbach [7], which is more restrictive than the hyperbolic space introduced in Goebel and Kirk [8] and more general than the hyperbolic space in Reich and Shafrir [9]. Concretely, $(E, d, W)$ is called a hyperbolic space if $(E, d)$ is a metric space and $W: E \times E \times[0,1] \rightarrow E$ is a function satisfying

(1) $\quad d(z, W(x, y, \alpha)) \leq \alpha d(z, x)+(1-\alpha) d(z, y)$;

(2) $\quad d(W(x, y, \alpha), W(x, y, \beta))=|\alpha-\beta| d(x, y)$;

(3) $W(x, y, \alpha)=W(y, x, 1-\alpha)$;

(4) $\quad d(W(x, z, \alpha), W(y, w, \alpha)) \leq(1-\alpha) d(x, y)+\alpha d(z, w)$

for all $x, y, z, w \in E$ and $\alpha, \beta \in[0,1]$. A nonempty subset $C$ of a hyperbolic space $E$ is convex if $W(x, y, \alpha) \in E(\forall x, y \in E)$ and $\alpha \in[0,1]$. The class of hyperbolic spaces contains normed spaces and convex subsets thereof, the Hilbert ball equipped with the hyperbolic metric [10], Hadamard manifolds as well as CAT(0) spaces in the sense of Gromov [11].

A hyperbolic space $E$ is uniformly convex if for $u, x, y \in E, r>0$ and $\epsilon \in(0,2]$, there exists $\delta \in(0,1]$ such that

$$
d\left(W\left(x, y, \frac{1}{2}\right), u\right) \leq(1-\delta) r,
$$

provided that $d(x, u) \leq r, d(y, u) \leq r$ and $d(x, y) \geq \epsilon r$.

A map $\eta:(0,+\infty) \times(0,2] \rightarrow(0,1]$ is called modulus of uniform convexity if $\delta=\eta(r, \epsilon)$ for given $r>0$. Besides, $\eta$ is monotone if it decreases with $r$, that is,

$$
\eta\left(r_{2}, \epsilon\right) \leq \eta\left(r_{1}, \epsilon\right), \quad \forall r_{2} \geq r_{1}
$$

Let $C$ be a nonempty subset of a metric space $(E, d)$. Recall that a mapping $T: C \rightarrow E$ is said to be nonexpansive if

$$
d(T x, T y) \leq d(x, y), \quad \forall x, y \in C
$$

Recall that $C$ is said to be a retraction of $E$ if there exists a continuous map $P: E \rightarrow C$ such that $P x=x$, for all $x \in C$. A map $P: E \rightarrow C$ is said to be a retraction if $P^{2}=P$. Consequently, if $P$ is a retraction, then $P y=y$ for all $y$ in the range of $P$.

Definition 2.1 ([12]) Let $C$ be a nonempty and closed subset of a metric space ( $E, d)$, a map $P: E \rightarrow C$ is a retraction, a mapping $T: C \rightarrow E$ is said to be 
(1) asymptotically nonexpansive nonself-mapping if there exists a sequence $\left\{k_{n}\right\} \subset[0,+\infty)$ with $k_{n} \rightarrow 1$ such that

$$
d\left(T(P T)^{n-1} x, T(P T)^{n-1} y\right) \leq k_{n} d(x, y), \quad \forall x, y \in C, n \geq 1
$$

(2) totally asymptotically nonexpansive nonself-mapping if there exist nonnegative sequences $\left\{\mu_{n}\right\},\left\{v_{n}\right\}$ with $\mu_{n} \rightarrow 0, v_{n} \rightarrow 0$ and a strictly continuous function $\zeta:[0,+\infty) \rightarrow[0,+\infty)$ with $\zeta(0)=0$ such that

$$
d\left(T(P T)^{n-1} x, T(P T)^{n-1} y\right) \leq d(x, y)+v_{n} \zeta(d(x, y))+\mu_{n}, \quad \forall x, y \in C, n \geq 1
$$

(3) uniformly $L$-Lipschitzian if there exists a constant $L>0$ such that

$$
d\left(T(P T)^{n-1} x, T(P T)^{n-1} y\right) \leq L d(x, y), \quad \forall x, y \in C, n \geq 1
$$

Remark 2.1 From the definitions above, we know that each nonexpansive mapping is an asymptotically nonexpansive nonself-mapping, and each asymptotically nonexpansive nonself-mapping is a totally asymptotically nonexpansive nonself-mapping.

To study our results in the general setup of hyperbolic spaces, we first collect some basic concepts. Let $\left\{x_{n}\right\}$ be a bounded sequence in hyperbolic space $E$. For $p \in E$, define a continuous functional $r\left(\cdot,\left\{x_{n}\right\}\right): E \rightarrow[0,+\infty)$ by

$$
r\left(p,\left\{x_{n}\right\}\right)=\limsup _{n \rightarrow \infty} d\left(p, x_{n}\right)
$$

The asymptotic radius $r\left(\left\{x_{n}\right\}\right)$ of $\left\{x_{n}\right\}$ is given by

$$
r\left(\left\{x_{n}\right\}\right)=\inf \left\{r\left(p,\left\{x_{n}\right\}\right): p \in E\right\} .
$$

The asymptotic radius $r_{C}\left(\left\{x_{n}\right\}\right)$ of $\left\{x_{n}\right\}$ with respect to $C \subset E$ is given by

$$
r_{C}\left(\left\{x_{n}\right\}\right)=\inf \left\{r\left(p,\left\{x_{n}\right\}\right): p \in C\right\} .
$$

The asymptotic center $A\left(\left\{x_{n}\right\}\right)$ of $\left\{x_{n}\right\}$ is the set

$$
A\left(\left\{x_{n}\right\}\right)=\left\{p \in E: r\left(p,\left\{x_{n}\right\}\right)=r\left(\left\{x_{n}\right\}\right)\right\} .
$$

The asymptotic center $A_{C}\left(\left\{x_{n}\right\}\right)$ of $\left\{x_{n}\right\}$ with respect to $C \subset E$ is the set

$$
A_{C}\left(\left\{x_{n}\right\}\right)=\left\{p \in C: r\left(p,\left\{x_{n}\right\}\right)=r_{C}\left(\left\{x_{n}\right\}\right)\right\} .
$$

A sequence $\left\{x_{n}\right\}$ in hyperbolic space $E$ is said to $\Delta$-converge to $p \in E$, if $p$ is the unique asymptotic center of $\left\{u_{n}\right\}$ for every subsequence $\left\{u_{n}\right\}$ of $\left\{x_{n}\right\}$. In this case, we call $p$ the $\triangle$-limit of $\left\{x_{n}\right\}$.

The following lemmas are important in our paper. 
Lemma 2.1 (see [13]) Let (E, $d, W)$ be a complete uniformly convex hyperbolic space with monotone modulus of uniform convexity, and let $C$ be a nonempty, closed, convex subset of $E$. Then every bounded sequence $\left\{x_{n}\right\}$ in $E$ has a unique asymptotic center with respect to $C$.

Lemma 2.2 (see $[13,14])$ Let $(E, d, W)$ be a uniformly convex hyperbolic space with monotone modulus of uniform convexity $\eta$. Let $q \in E$ and $\left\{\alpha_{n}\right\}$ be a sequence in $[a, b]$ for some $a, b \in(0,1)$. If $\left\{x_{n}\right\}$ and $\left\{y_{n}\right\}$ are sequences in $E$ such that $\limsup _{n \rightarrow \infty} d\left(x_{n}, q\right) \leq c$, $\limsup _{n \rightarrow \infty} d\left(y_{n}, q\right) \leq c$, and $\lim _{n \rightarrow \infty} d\left(W\left(x_{n}, y_{n}, \alpha_{n}\right), q\right)=c$ for some $c \geq 0$, then $\lim _{n \rightarrow \infty} d\left(x_{n}, y_{n}\right)=0$.

Lemma 2.3 (see [12]) Let $C$ be a nonempty, closed, convex subset of a uniformly convex hyperbolic space, and let $\left\{x_{n}\right\}$ be a bounded sequence in $C$ such that $A\left(\left\{x_{n}\right\}\right)=\{p\}$ and $r\left(\left\{x_{n}\right\}\right)=\rho$. If $\left\{y_{k}\right\}$ is another sequence in $C$ such that $\lim _{k \rightarrow \infty} r\left(y_{k},\left\{x_{n}\right\}\right)=\rho$, then $\lim _{k \rightarrow \infty} y_{k}=p$.

Lemma 2.4 Let $\left\{\alpha_{n}\right\},\left\{\beta_{n}\right\}$, and $\left\{\gamma_{n}\right\}$ be sequences of nonnegative numbers such that

$$
\alpha_{n+1} \leq\left(1+\beta_{n}\right) \alpha_{n}+\gamma_{n}, \quad \forall n \geq 1
$$

If $\sum_{n=1}^{+\infty} \beta_{n}<+\infty$ and $\sum_{n=1}^{+\infty} \gamma_{n}<+\infty{ }_{n}$, then $\lim _{n \rightarrow+\infty} \alpha_{n}$ exists. If there exists a subsequence $\left\{\alpha_{n_{k}}\right\} \subset\left\{\alpha_{n}\right\}$ such that $\lim _{k \rightarrow+\infty} \alpha_{n_{k}}$, then $\lim _{n \rightarrow+\infty} \alpha_{n}=0$.

\section{Main results}

Now we modify a classical Kuhfittig iteration algorithm in the general setup of hyperbolic space, and prove a $\triangle$-convergence theorem for the following implicit iterative scheme:

$$
x_{n}=P W\left(x_{n-1}, T(P T)^{n-1} x_{n}, \alpha_{n}\right), \quad x \in C, n \geq 1,
$$

where $C$ is a nonempty closed and convex subset of a complete uniformly hyperbolic space $E, T: C \rightarrow E$ is a uniformly $L$-Lipschitzian and $\left(\left\{k_{n}\right\}\right)$-asymptotically nonexpansive nonself-mapping with $k_{n} \in[1,+\infty)$ and $\lim _{n \rightarrow+\infty} k_{n}=1$, and $\alpha_{n} \in(0,1)$ such that $\alpha_{n} k_{n}<1$. $P$ is nonexpansive retraction of $E$ onto $C$.

Remark 3.1 For $\alpha_{n} \in(0,1)$ and a fixed $u \in C$, define the mapping $K_{n}: C \rightarrow E$ by

$$
K_{n}(x)=P W\left(u, T(P T)^{n-1} x, \alpha_{n}\right), \quad x \in C .
$$

It can be seen obviously that $K_{n}$ is contraction on $C$. Indeed, for $x, y \in C$, we have

$$
\begin{aligned}
d\left(K_{n}(x), K_{n}(y)\right) & =d\left(P W\left(u, T(P T)^{n-1} x, \alpha_{n}\right), P W\left(u, T(P T)^{n-1} y, \alpha_{n}\right)\right) \\
& \leq d\left(W\left(u, \alpha_{n}, \alpha_{n}\right), W\left(u, T(P T)^{n-1} y, \alpha_{n}\right)\right) \\
& \leq \alpha_{n} d\left(T(P T)^{n-1} x, T(P T)^{n-1} y\right) \\
& \leq \alpha_{n} k_{n} d(x, y) .
\end{aligned}
$$


Therefore, $K_{n}$ is a contraction mapping, that is,

$$
x_{n}=P W\left(x_{n-1}, T(P T)^{n-1} x_{n}, \alpha_{n}\right), \quad n \geq 1,
$$

is valid under the condition $\alpha_{n} k_{n}<1$.

Theorem 3.1 Let E be a complete hyperbolic space, $C$ be a nonempty, bounded, closed, convex subset of $E$ and $P: E \rightarrow C$ be the nonexpansive retraction. Let $T: C \rightarrow E$ be $\left\{k_{n}\right\}$-asymptotically nonexpansive nonself-mapping with sequence $\left\{k_{n}\right\} \subset[1,+\infty)$ and $\lim _{n \rightarrow+\infty} k_{n}=1$ such that $T$ is uniformly L-Lipschitz continuous, satisfying the following conditions:

(i) $\sum_{n=1}^{+\infty}\left(k_{n}-1\right)<+\infty$;

(ii) $\alpha_{n} k_{n}<1$ for all $n \geq 1$;

(iii) there exist constants $a, b \in(0,1)$ with $0<b(1-a)<\frac{1}{2}$ such that $\left\{\alpha_{n}\right\} \subset[a, b]$.

Define $\left\{x_{n}\right\}$ as follows: $x_{0} \in C$,

$$
x_{n}=P W\left(x_{n-1}, T(P T)^{n-1} x_{n}, \alpha_{n}\right), \quad n \geq 1,
$$

and $F(T) \neq \emptyset$. Then the sequence $\left\{x_{n}\right\} \triangle$-converges to a point $p^{*} \in F(T)$.

Proof (I) First, we prove that $\lim _{n \rightarrow \infty} d\left(x_{n}, p\right)(\forall p \in F(T))$ and $\lim _{n \rightarrow \infty} d\left(x_{n}, F(T)\right)$ exist, respectively.

Since $T: C \rightarrow E$ is $\left\{k_{n}\right\}$-asymptotically nonexpansive nonself-mapping with sequence $\left\{k_{n}\right\} \subset[1,+\infty)$ and $\lim _{n \rightarrow+\infty} k_{n}=1$, from Definition 2.1(1), for any $x, y \in C$, we have

$$
d\left(T(P T)^{n-1} x, T(P T)^{n-1} x\right) \leq k_{n} d(x, y), \quad \forall n \geq 1 .
$$

For each $p \in F(T)$, it follows from (3.1) and (2.1) that

$$
\begin{aligned}
d\left(x_{n}, p\right) & =d\left(P W\left(x_{n-1}, T(P T)^{n-1} x_{n}, \alpha_{n}\right), p\right) \\
& \leq d\left(W\left(x_{n-1}, T(P T)^{n-1} x_{n}, \alpha_{n}\right), p\right) \\
& \leq\left(1-\alpha_{n}\right) d\left(x_{n-1}, p\right)+\alpha_{n} d\left(T(P T)^{n-1} x_{n}, p\right) \\
& \leq\left(1-\alpha_{n}\right) d\left(x_{n-1}, p\right)+\alpha_{n} k_{n} d\left(x_{n}, p\right),
\end{aligned}
$$

which indicates

$$
d\left(x_{n}, p\right) \leq\left(1+\frac{\alpha_{n}\left(k_{n}-1\right)}{1-\alpha_{n} k_{n}}\right) d\left(x_{n-1}, p\right) .
$$

From condition (iii), we have

$$
d\left(x_{n}, p\right) \leq\left(1+\frac{b\left(k_{n}-1\right)}{1-b k_{n}}\right) d\left(x_{n-1}, p\right) .
$$

Since $\lim _{n \rightarrow \infty}\left(1-b k_{n}\right)=1-b$, there exists an integer $n_{0}$ such that $1-b k_{n} \geq \frac{1-b}{2}$ for all $n>n_{0}$. Hence we have

$$
d\left(x_{n}, p\right) \leq\left(1+\delta_{n}\right) d\left(x_{n-1}, p\right), \quad \forall n>n_{0},
$$


and so

$$
d\left(x_{n}, F(T)\right) \leq\left(1+\delta_{n}\right) d\left(x_{n-1}, F(T)\right), \quad \forall n>n_{0},
$$

where $\delta_{n}:=\frac{2 b\left(k_{n}-1\right)}{1-b}$. By condition (i), we get $\sum_{n=1}^{+\infty} \delta_{n}<+\infty$. Therefore, from Lemma 2.4, $\lim _{n \rightarrow \infty} d\left(x_{n}, p\right)(\forall p \in F(T))$ and $\lim _{n \rightarrow \infty} d\left(x_{n}, F(T)\right)$ exist.

(II) Next, we prove that $d\left(x_{n}, T x_{n}\right) \rightarrow 0$ (as $\left.n \rightarrow \infty\right)$.

For $p \in F(T)$, according to the proof of (I), we know that $\lim _{n \rightarrow \infty} d\left(x_{n}, p\right)$ exists. Assume that

$$
\lim _{n \rightarrow \infty} d\left(x_{n}, p\right)=r \geq 0
$$

From (3.4) and (3.6), we get

$$
\begin{aligned}
r & =\lim _{n \rightarrow \infty} d\left(x_{n}, p\right) \\
& \leq \lim _{n \rightarrow \infty} d\left(W\left(x_{n-1}, T(P T)^{n-1} x_{n}, \alpha_{n}\right), p\right) \\
& \leq \lim _{n \rightarrow \infty}\left(\left(1+\delta_{n}\right) d\left(x_{n-1}, p\right)\right)=r,
\end{aligned}
$$

which implies that

$$
\lim _{n \rightarrow \infty} d\left(W\left(x_{n-1}, T(P T)^{n-1} x_{n}, \alpha_{n}\right), p\right)=r .
$$

In addition, since

$$
d\left(T(P T)^{n-1} x_{n}, p\right) \leq k_{n} d\left(x_{n}, p\right), \quad \forall n \geq 1,
$$

from (3.6), we have

$$
\limsup _{n \rightarrow \infty} d\left(T(P T)^{n-1} x_{n}, p\right) \leq r
$$

It follows from (3.6)-(3.8) and Lemma 2.2 that

$$
\lim _{n \rightarrow \infty} d\left(x_{n-1}, T(P T)^{n-1} x_{n}\right)=0 .
$$

We obtain

$$
\begin{aligned}
d\left(x_{n}, x_{n-1}\right) & =d\left(P W\left(x_{n-1}, T(P T)^{n-1} x_{n}, \alpha_{n}\right), x_{n-1}\right) \\
& \leq \alpha_{n} d\left(T(P T)^{n-1} x_{n}, x_{n-1}\right) \rightarrow 0 \quad(\text { as } n \rightarrow \infty) .
\end{aligned}
$$

Hence, from (3.9) and (3.10), we get

$$
\lim _{n \rightarrow \infty} d\left(x_{n}, T(P T)^{n-1} x_{n}\right)=0 .
$$


Since $T$ is uniformly $L$-Lipschitzian, we have

$$
\begin{aligned}
d\left(x_{n}, T x_{n}\right) \leq & d\left(x_{n}, x_{n+1}\right)+d\left(x_{n+1}, T(P T)^{n} x_{n+1}\right) \\
& +d\left(T(P T)^{n} x_{n+1}, T(P T)^{n} x_{n}\right)+d\left(T(P T)^{n} x_{n}, T x_{n}\right) \\
\leq & (1+L) d\left(x_{n}, x_{n+1}\right)+d\left(x_{n+1}, T(P T)^{n} x_{n+1}\right)+d\left(T(P T)^{n} x_{n}, T x_{n}\right) \\
\leq & (1+L) d\left(x_{n}, x_{n+1}\right)+d\left(x_{n+1}, T(P T)^{n} x_{n+1}\right)+L d\left((P T)^{n} x_{n}, x_{n}\right) \\
\leq & (1+L) d\left(x_{n}, x_{n+1}\right)+d\left(x_{n+1}, T(P T)^{n} x_{n+1}\right)+L d\left(T(P T)^{n-1} x_{n}, x_{n}\right) .
\end{aligned}
$$

It follows from (3.11) and (3.12) that

$$
\lim _{n \rightarrow \infty} d\left(x_{n}, T x_{n}\right)=0
$$

(III) Now we prove that $\left\{x_{n}\right\} \Delta$-converges to a point $p^{*} F(T)$.

Since $\left\{x_{n}\right\}$ is bounded, by Lemma 2.1, it has a unique asymptotic center $A_{C}\left(\left\{x_{n}\right\}\right)=\left\{p^{*}\right\}$. If $\left\{u_{n}\right\}$ is any subsequence of $\left\{x_{n}\right\}$ with $A_{C}\left(\left\{u_{n}\right\}\right)=\{q\}$, then, from (3.12), we have

$$
\lim _{n \rightarrow \infty} d\left(u_{n}, T u_{n}\right)=0 .
$$

We claim that $q \in F(T)$. In fact, for any $m, n \geq 1$,

$$
\begin{aligned}
d\left(T(P T)^{m-1} q, u_{n}\right) \leq & d\left(T(P T)^{m-1} q, T(P T)^{m-1} u_{n}\right) \\
& +d\left(T(P T)^{m-1} u_{n}, T(P T)^{m-2} u_{n}\right)+\cdots+d\left(T u_{n}, u_{n}\right) \\
\leq & k_{m} d\left(q, u_{n}\right)+L d\left(T u_{n}, u_{n}\right)+\cdots+d\left(T u_{n}, u_{n}\right) .
\end{aligned}
$$

From (3.13), we get

$$
\limsup _{n \rightarrow \infty} d\left(T(P T)^{m-1} q, u_{n}\right) \leq \limsup _{n \rightarrow \infty} k_{m} d\left(q, u_{n}\right)=k_{m} r\left(q,\left\{u_{n}\right\}\right),
$$

and so

$$
\limsup _{m \rightarrow \infty} d\left(T(P T)^{m-1} q, u_{n}\right) \leq r\left(q,\left\{u_{n}\right\}\right) .
$$

By the definition of the asymptotic center $A_{c}\left\{u_{n}\right\}$ of a bounded sequence $\left\{u_{n}\right\}$ with respect $C$, we have

$$
r\left(q,\left\{u_{n}\right\}\right) \leq r\left(x,\left\{u_{n}\right\}\right), \quad \forall x \in C .
$$

This implies that

$$
\liminf _{m \rightarrow \infty} r\left(T(P T)^{m-1} q,\left\{u_{n}\right\}\right) \leq r\left(q,\left\{u_{n}\right\}\right) .
$$

Therefore, we have

$$
\lim _{m \rightarrow \infty} r\left(T(P T)^{m-1} q,\left\{u_{n}\right\}\right)=r\left(q,\left\{u_{n}\right\}\right) .
$$


By Lemma 2.3, one shows that $\lim _{m \rightarrow \infty} T(P T)^{m-1} q=q$. Because $T$ is uniformly continuous, we have

$$
T q=T \lim _{m \rightarrow \infty} T(P T)^{m-1} q=T \lim _{m \rightarrow \infty} P T(P T)^{m-1} q=\lim _{m \rightarrow \infty} T(P T)^{m} q=q
$$

Consequently, $q \in F(T)$. By the uniqueness of asymptotic centers, we get $p^{*}=q$. It implies that $p^{*}$ is the unique asymptotic of $\left\{u_{n}\right\}$ for each subsequence $\left\{u_{n}\right\} \subset\left\{x_{n}\right\}$, that is, $\left\{x_{n}\right\} \triangle$-converges to a point $p^{*} \in F(T)$. The proof of Theorem 3.1 is completed.

From Remark 2.1, we have the following result.

Corollary 3.1 Let E be a complete hyperbolic space, $C$ be a nonempty, bounded, closed, convex subset of $E$, and $P: E \rightarrow D$ be the nonexpansive retraction. Let $T: C \rightarrow E$ be nonexpansive nonself-mapping such that $T$ be uniformly L-Lipschitz continuous. Define $\left\{x_{n}\right\}$ as follows: $x_{0} \in C$,

$$
x_{n}=P W\left(x_{n-1}, T(T P)^{n-1} x_{n}, \alpha_{n}\right), \quad n \geq 1 .
$$

If there exist constants $a, b \in(0,1)$ with $0<b(1-a)<\frac{1}{2}$ such that $\left\{\alpha_{n}\right\} \subset[a, b]$, and $F(T) \neq \emptyset$, then the sequence $\left\{x_{n}\right\} \triangle$-converges to a point $p^{*} \in F(T)$.

\section{Competing interests}

The authors declare that they have no competing interests.

\section{Authors' contributions}

All authors contributed equally to the writing of this paper. All authors read and approved the final manuscript.

\section{Acknowledgements}

The authors are very grateful to both reviewers for carefully reading this paper and their comments.

Received: 15 February 2014 Accepted: 19 July 2014 Published: 19 Aug 2014

\section{References}

1. Lim, TC: Remarks on some fixed point theorems. Proc. Am. Math. Soc. 60, 179-182 (1976)

2. Kirk, WA, Panyanak, B: A concept of convergence in geodesic spaces. Nonlinear Anal. 68, 3689-3696 (2008)

3. Dhompongsa, S, Panyanak, B: On $\triangle$-convergence theorem in CAT(0) spaces. Comput. Math. Appl. 56(10), 2572-2579 (2008)

4. Abbas, M, Thakur, BS, Thakur, D: Fixed points of asymptotically nonexpansive mapping in the intermediate sense in CAT(0) spaces. Commun. Korean Math. Soc. 28(1), 107-121 (2013)

5. Yang, L, Zhao, FH: Srong and $\Delta$-convergence theorems for total asymptotically nonexpansive nonself mappings in CAT(0) spaces. J. Inequal. Appl. 2013, Article ID 557 (2013)

6. Wan, L: $\Delta$-Convergence for mixed-type total asymptotically nonexpansive mappings in hyperbolic spaces. J. Inequal. Appl. 2013, Article ID 553 (2013)

7. Kohlenbach, U: Some logical metatheorems with applications in functional analysis. Trans. Am. Math. Soc. 357, 89-128 (2005)

8. Goebel, K, Kirk, WA: Iteration processes for nonexpansive mappings. In: Singh, SP, Thomeier, S, Watson, B (eds.) Topological Methods in Nonlinear Functional Analysis. Contemp. Math., vol. 21, pp. 115-123. Am. Math. Soc., Providence (1983)

9. Reich, S, Shafrir, I: Nonexpansive iterations in hyperbolic spaces. Nonlinear Anal. 15, 537-558 (1990)

10. Goebel, K, Reich, S: Uniform Convexity, Hyperbolic Geometry, and Nonexpansive Mappings. Dekker, New York (1984)

11. Bridson, M, Haefliger, A: Metric Spaces of Non-Positive Curvature. Springer, Berlin (1999)

12. Wang, L, Chang, SS, Ma, Z: Convergence theorem for total asymptotically nonexpansive nonself mappings in CAT(0) space. J. Inequal. Appl. 2013, Article ID 135 (2013)

13. Khan, AR, Fukharuddin, H, Khan, MAA: An implicit algorithm for two finite families of nonexpansive maps in hyperbolic space. Fixed Point Theory Appl. 2012, Article ID 54 (2012)

14. Leustean, L: Nonexpansive iterations uniformly covex W-hyperbolic spaces. In: Leizarowitz, A, Mordukhovich, BS, Shafrir, I, Zaslavski, A (eds.) Nonlinear Analysis and Optimization I. Nonlinear Analysis. Contemporary Math., vol. 513 pp. 193-209. Am. Math. Soc, Providence (2010) 
10.1186/1029-242X-2014-303

Cite this article as: $Y i$ and $B o: \triangle$-Convergence analysis of improved Kuhfittig iterative for asymptotically

nonexpansive nonself-mappings in W-hyperbolic spaces. Journal of Inequalities and Applications 2014, 2014:303

Submit your manuscript to a SpringerOpen ${ }^{\circ}$ journal and benefit from:

- Convenient online submission

- Rigorous peer review

- Immediate publication on acceptance

- Open access: articles freely available online

- High visibility within the field

- Retaining the copyright to your article

Submit your next manuscript at $\gg$ springeropen.com 